\begin{tabular}{|c|c|c|}
\hline BENTHAM OPEN & $\begin{array}{c}\text { The Open Construction and Building } \\
\text { Technology Journal }\end{array}$ & $\begin{array}{l}\text { The Open } \\
\text { Costruction \& Building } \\
\text { Tecthology lournal }\end{array}$ \\
\hline CrossMark & $\begin{array}{l}\text { Content list available at: www.benthamopen.com/ТОВСТJ/ } \\
\text { DOI: } 10.2174 / 1874836801610010259\end{array}$ & 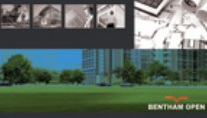 \\
\hline
\end{tabular}

\title{
Ecosmart Reinforcement for a Masonry Polycentric Pavilion Vault
}

\author{
Vincenzo Gattulli ${ }^{*}$, , Francesco Potenza $^{1}$, Jessica Toti ${ }^{1}$, Filippo Valvona ${ }^{1}$ and Giancarlo Marcari ${ }^{2}$ \\ ${ }^{\text {I}}$ Department of Civil, Architectural and Environmental Engineering, University of L'Aquila, L'Aquila, Italy \\ ${ }^{2}$ Department of Structural and Geotechnical Engineering, Faculty of Engineering, University of Rome, Rome, Italy
}

Received: January 15,2015

Revised: May 15, 2015

Accepted: July 06, 2015

\begin{abstract}
In the cultural life of modern societies great importance has acquired the preservation of existing and, in particular, ancient architectural heritage. With the inherent historical aspects, the economic implications have to be taken into account as well. Indeed, especially European cities and countries receive significant economic advantages by the existence of monuments and ancient suburbs. In this context, structural maintenance, strengthening and monitoring has gained an important academic and professional impulse. The present paper aims to present the results of a real scale experimental work regarding the application of an innovative seismic retrofitting technique for masonry walls and vaults by Hydraulic Lime Mortar strengthened by Glass Fiber Reinforced Polymer textile grids (HLM-GFRP) embedding new sensing systems as fiber optical sensors. The real scale specimen is a masonry polycentric pavilion vault that was damaged during the L'Aquila earthquake of April 2009. The need of eco compatibility of bonding material with masonry support implies the use of HLM-GFRP as strengthening system. On the other hand, the use of Fiber Bragg Grating (FBG) has a large number of advantages in opposite to electrical measuring methods. Example are: small sensor dimensions, low weight as well as high static and dynamic resolution of measured values, distributed sensing feature allowing to detect anomalies in load transfer between reinforcement and substrate and the location of eventual cracking patterns. A suitable Finite Element (FE) model is developed both to assess the effectiveness of the HLM-GFRP strengthening layers in retrofitting of the masonry vault and to define the strain field essential to the design of the FBG sensors network.
\end{abstract}

Keywords: Experimental testing, Fibre Bragg Gratings, Lime mortar, Masonry structures, Structural monitoring,Vault.

\section{INTRODUCTION}

Nowadays around the world, most of the built environment is composed, on average, by quite and very old structures. Thus, the development of novel rehabilitation and strengthening techniques has acquired great importance during the last decades within a new framework. Indeed, on one hand the improvements of scientific knowledge regarding the structural behavior of civil constructions have driven to more precise evaluations of the capacity limits for safety or damage reduction of structures and their retrofitting and on the other hand, many cases of complete structural inadequacy for both ordinary and non-ordinary events, in service structures inadequate for the current static loads and, large stocks of structures and infrastructures damaged after moderate seismic events were found. Fiber Reinforced Polymers (FRP) systems can be used for the strengthening or retrofitting of existing concrete, steel, masonry and wood structures to resist higher design loads (earthquake loads), correct deterioration-related damage or increase members ductility. These advanced composite materials are being developed from fibers, polymers, cement or lime based binder matrices, metals (steel strands) and their composition.

While composites have been used in building industry for several millennia, the conscious and systematic application of fiber reinforced composites for rehabilitation and strengthening of structures is relatively new. Externally bonded FRP systems have dramatically increased worldwide, from a few ten-twenty years ago to several thousand today [1]. The FRP composites gain their strength largely from the fibers, which are usually glass, carbon, aramid and steel. In the last few years, the scientific community has shown a particular interest in the use of natural composite

\footnotetext{
* Address correspondence to this author at the Department of Civil, Architectural and Environmental Engineering, University of L'Aquila, L'Aquila, Italy; Tel: +39-0862-43-4511; Fax: +39-0862-43-4548; E-mail: vincenzo.gattulli@univaq.it
} 
materials, focusing on their cheapness, recyclability, renewability and environmental sustainability (bio-compatibility) respect to common man-made fibers [2,3]. Within natural fibers can be classified those derived from plants like flax, cotton, hemp, jute, sisal and some other but also from rocks as basalt. Strengthening composites are lightweight, noncorrosive, fire-retardants (except vegetal fibers), non-magnetic and exhibit high tensile strength. Additionally, these materials are readily available in several forms ranging from factory made laminates and bars to dry fiber sheets or textiles that can be wrapped to conform to each geometry of the structures. Finally, the main features of these materials are high strength-to-weight and stiffness-to-weight ratios, fast and easy application. FRPs have been used primarily in concrete structures requiring improved corrosion resistance or electromagnetic transparency as internal non-prestressed and prestressed reinforcements. They have been under development since as early as the 1960s in the United States [4] and the 1970s in Europe [5]. Internal FRP reinforcements have been fabricated in a variety of one-dimensional bars (smooth and bond-improved) and multidimensional shapes [6]. To date, most commercially prefabricated multidimensional reinforcements are orthogonal, two-dimensional grids and multi-axial nets. One-dimensional FRP reinforcements are typically employed for bending stress case of beams. Cosenza et al., GangaRao et al. [7, 8] review a number of one-dimensional FRP bar products. Grid reinforcements have been made by winding resin-impregnated bundles of fibers into prescribed two and three-dimensional shapes using a variety of manufacturing processes [6]. The grids are often used as flat, two-dimensional flexural reinforcement in slabs or three-dimensional cages for combined shear and axial reinforcement in beams. Indeed, the major use and dissemination of these materials is certainly in externally bonded applications. Historically, composites were first applied as flexural strengthening materials for Reinforced Concrete (RC) bridges [9, 10] and as confining reinforcement of RC columns [11, 12]. Developments since the first research efforts in the mid-1980s have been tremendous. The range of applications has expanded, over reinforced concrete, to include masonry, timber and steel structures [6, 13 - 28]. In the recent past, new reinforcement systems have been developed including Fiber Reinforced Grout (FRG), Fiber Reinforced Cement (FRC), Steel Reinforced Grout (SRG) and Steel Reinforced Cement (SRC). The inorganic matrices, even though are not able to guarantee the same adhesion property of the epoxy resins reducing tensile strength, may offer numerous advantages in terms of durability, toxicity, breathability and resistance to fire, as well as more eco compatibility with support. These ones are characterized by an inorganic bonding matrix; in particular, composites marked by final G make use of grout (natural lime) as glue while those marked by final $\mathrm{C}$ make use of cement. In the present work, glass fiber reinforced grout (or cement) reinforcement is considered. Several experimental tests have shown the effectiveness of the FRP material as strengthening technique; however, there are still many unresolved and not sufficiently studied questions regarding their long term behavior and durability and the adhesion capacity for bonding inorganic matrices. The use of a Structural Health Monitoring System (SHMS), in order to evaluate the durability of the composite structures in real time and ensure its security, becomes essential. Several types of advanced sensing technologies based on piezoelectric sensors or fiber optical sensors (FOSs) have been developed for this purpose so far [29, 30]. In particular, the FOSs are often preferred for embedding in FRP materials for a variety of advantages that include: durability in harsh environment, immunity to electromagnetic interference, small size and higher material compatibility. The FOS technologies have been used for strain and temperature sensing of FRP strengthening members by either embedding into or bonding onto the structures. A number of the activities pertain to the development of distributed or multiplexing sensors, involving techniques based on Fabry-Perot cavities [31], Brillouin scattering [32] and Fiber Bragg Grating (FBG) [33]. In particular, the FBG sensor, thanks to its localized high precision measurements, represents the most widely used technology among OFSs. Shultz et al. [34] employed long gauge length FBG sensors to monitor Carbon Fiber Reinforced Polymers (CFRP) strengthened bridge members. The FBG sensor was mounted into capillary tubes made of polyether-ehter-ketone. Kalamkarov [35] developed a smart FRP rod by embedded FBG and Fabry-Perot fiber optic sensor for strain monitoring in innovative bridges. Lau et al. [36] proposed a theoretical model in order to evaluate in a FRP strengthened concrete beam the strain between the bare fiber and the host material for different adhesive thickness and modulus of the protective coating of the embedded FBG sensor. Wang et al. [37] studied the flexural behavior of a FRP-concrete composite beam with two pre-embedded FBG strain sensors during its fabrication process; this research demonstrated that the smart composite structure is able to monitor its longitudinal strains in serviceability limit state as well as in strength limit state. Recently, cost-effective systems including Brillouin Optical Time Domain Analysis (BOTDA) sensors have been developed and applied to monitor large civil structures. In comparison with other FOS technologies, Brillouin sensing system is characterized by lower sensitivity, repeatability and accuracy, but the advantage of providing a real distributed sensing can easily overcome these defects. In fact, the huge amount of measurement points can help to understand the whole structure behavior much better than a limited number of high precision data, allowing the detection of local phenomena. About this monitoring technique, Bastianini et al. [38] investigated on the use of Brillouin technology in detecting anomalies in load transfer between FRP laminates and 
cohesive substrate and the location of eventual cracking patterns in a FRP-strengthened historic masonry building. To date, one of the most important research work on FRP-embedded sensing systems is represented by the Polytect Project [39]. POLYfunctional TEChnical Textiles (POLYTECT) against natural hazards is an integrated project for small to medium enterprises. Different applications require different types of measurements and sensors. Within the project a range of sensors and sensing acquisition systems that include the materials Glass Optical Fibers (GOF), Plastic Optical Fibers (POF), and sensitive textile fibers and which employ the sensing techniques of FBG, Optical Time Domain Reflectometry (OTDR), distributed Brillouin sensing, piezoelectric sensing have been developed. As tests case, a variety of geotechnical and masonry applications have been taken into account.

In the present research work, FBG sensors have been adopted and glued to reinforcement, made by the Hydraulic Lime Mortar (HLM) and GFRP grids. The strengthened specimen is a masonry polycentric pavilion vault damaged during L'Aquila earthquake. The present research focuses on the development of computational tools and the design of reinforcement systems for the analysis and structural health monitoring of masonry structures subjected to dynamic loads. In particular, finite element (FE) models using multilayer elements are developed both to assess the effectiveness of the HLM-GFRP strengthening layers in retrofitting of a masonry vault and to define the strain field essential to the design of the FBG sensor locations and sizes.

\section{MONITORING WITH FIBER BRAGG GRATING (FBG) SENSORS}

Structural integration of fiber-optic sensing systems represents a new branch of modern civil engineering. FOSs have a number of advantages over their electrical counterparts. In the recent years FBG sensors have undergone a fast development due to their own technical properties. FBG sensors have attracted interest from civil structure communities for structural health, vibration and seismic response monitoring. This kind of sensors are immune to electromagnetic interference, are lightweight and have small physical dimensions, suitable for being embedded into or attached to a structure. No wires are required to connect sensors to control system as the fibers themselves act as both the measuring elements and the signal propagation ducts. FBGs offer a unique advantage of single ended connection to control systems because only reflected signals from FBGs are important for demodulation. They possess excellent resolution and range, water and corrosion resistance, ability to be multiplexed, immunity to harsh water conditions, compact sensor and harness size and reasonable cost per channel. Long-term strain measures are pivotal in avoiding unexpected failure or cracking and can be useful in evaluating design limits of the structures. On the other hand, the high cost of maintenance, lack of precision in visual inspection and susceptibility of common sensors to harsh environmental conditions has made SHM a necessity. For existing structures, FBG sensors can be attached (glued) onto the structure surface, whereas for new structures, these sensors can be embedded into the structure, with some cure, during the construction phase. The information from such SHM systems can provide early warning for compromised integrity of structures and thus help avoid severe losses. Such information is also helpful to adapt and update newer designs of current and similar structures. One important reason for continuing diffusion of FBG has to be seen in the ability of Multiplexing [40]. One FBG can measure strain or temperature changes only at one point. But there is the possibility to distribute several Bragg Gratings in one optical fiber. Clearly this property offer a distributed sensing along the structure with only one optical fiber [41].

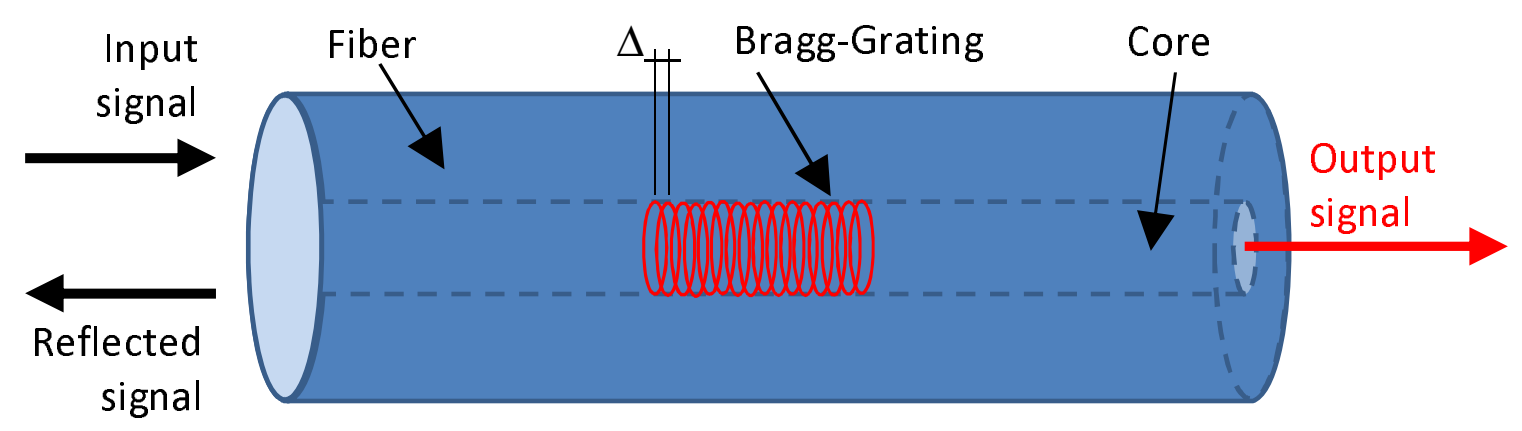

Fig. (1). Glass Fiber with Bragg Grating. 


\subsection{Principle of Operation of FBG Sensors}

A Bragg grating (Fig. 1) consists of a periodic sequence of artificial and equidistant refraction switches in the core of an optical fiber [42]. For mechanical protection the glass fiber gets an additional coat of synthetic material.

Light with the Bragg wavelength $\lambda_{\mathrm{B}}$ will be reflected. This means that light of inducted spectrum will be reflected according to equation (1):

$$
\lambda_{B}=2 \eta_{\text {eff }} \Delta
$$

where $\lambda_{\mathrm{B}}=$ Bragg wavelength, $\eta_{\text {eff }}=$ effective refraction index and $=\Delta$ period of diffraction grating. This term of the light spectrum will be missing in the penetrated array (output signal). With equation (1) it is possible to clarify the measuring principle of FBG. A change of the period of diffraction grating results in an adjustment of the Bragg wavelength. Hence other spectra of light will be reflected. These modifications can be activated by strain or temperature and then changes can be measured. The change of strain in the optical fiber can be explained with equation (2)

$$
\Delta \lambda_{B}=\lambda_{B}\left(1-p_{e}\right) \Delta \varepsilon
$$

where $\Delta \lambda_{B}=$ change of Bragg wavelength, $p_{e}=$ photo elastic component and $\Delta \varepsilon=$ change of strain. Besides the monitoring of strain in structural elements the temperature measurement will be of interest. Also in this area $\mathrm{FBG}_{\mathrm{S}}$ can be used. With equation (3) the change of temperature can be considered.

$$
\Delta \lambda_{B}=\lambda_{B}(1-\xi) \Delta T
$$

where $\alpha=$ thermo-elastic coefficient, $\xi=$ thermo-optic coefficient and $\Delta \mathrm{T}=$ change of temperature. Equation (3) shows that the simultaneous change of strain and temperature results in a modification of wavelength. With equation (2) and equation (3) the following combination is feasible in which strain and temperature are considered.

$$
\Delta \varepsilon=\frac{1}{1-p_{e}}\left(\frac{\Delta \lambda_{B}}{\lambda_{B}}-(\alpha+\xi) \Delta T\right)
$$

For explicit strain measurements it will be necessary to perform a compensation of the temperature influence [42, 43]. One possibility is an additional FBG only for temperature measurement in mechanically decoupled areas; furthermore simple techniques are available in literature [43]. These FBG can be emblazed at the same optical fiber. Essentially, when the strain or temperature variation of the structure occurs, the surface mounted or embedded optical fiber sensor will expand and contract. Accordingly with the change of the length of the fiber (and also the period $\Delta$ ), the optical fiber sensor modulates the light and reflects back a different signal with another $\lambda_{\mathrm{B}, \mathrm{f} \cdot}$. The analytical unit can calculate $\Delta \lambda_{\mathrm{B}}$ and, being known all quantities in equation (4), the strain measure can be returned back.
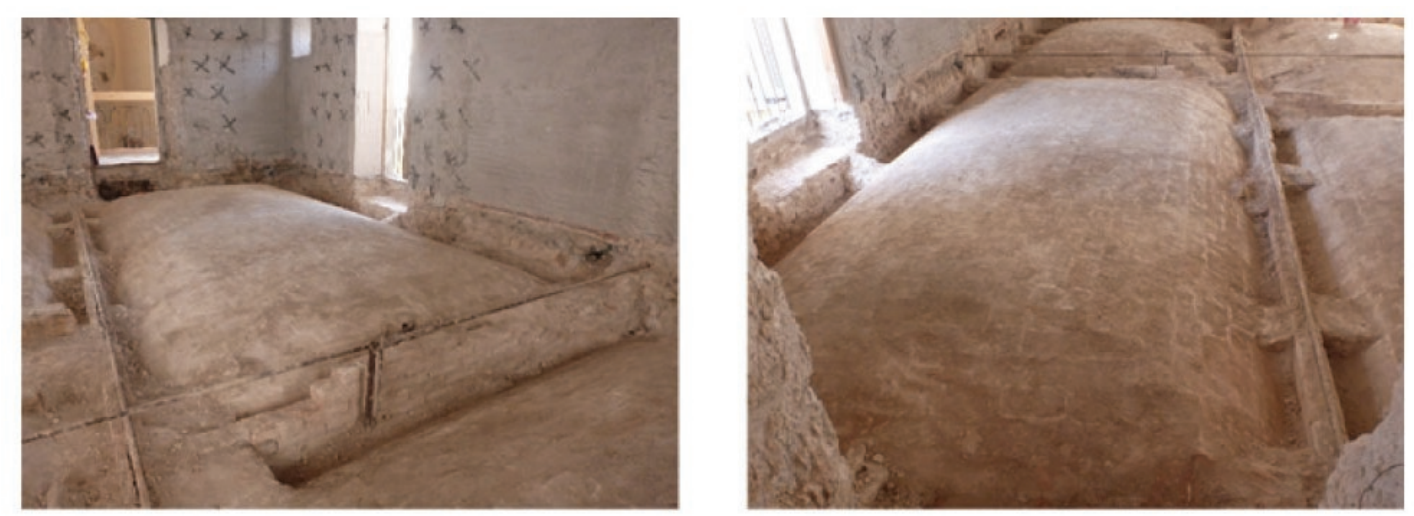

Fig. (2). Mansonry pavillon vault during retrofitting works. 


\section{NUMERICAL MODELLING OF THE MANSORY POLYCENTRIC PAVILLON VAULT}

In order to build the numerical model of the structure is a priority the exhaustive definition of the geometry and the mechanical properties of the constituting material. The studied pavilion vault is depicted in Fig. (2) by photos taken from the upper part of the vault during the rehabilitation phases.

The precise reconstruction of the median arc profiles for both orthogonal directions is made by trilateration method. A certain number of measurements are realized in longitudinal (long) and transversal (short) direction. Finally, the median profiles of the arcs are given back. In Fig. (3) is shown the vault geometry deduced by the relief.

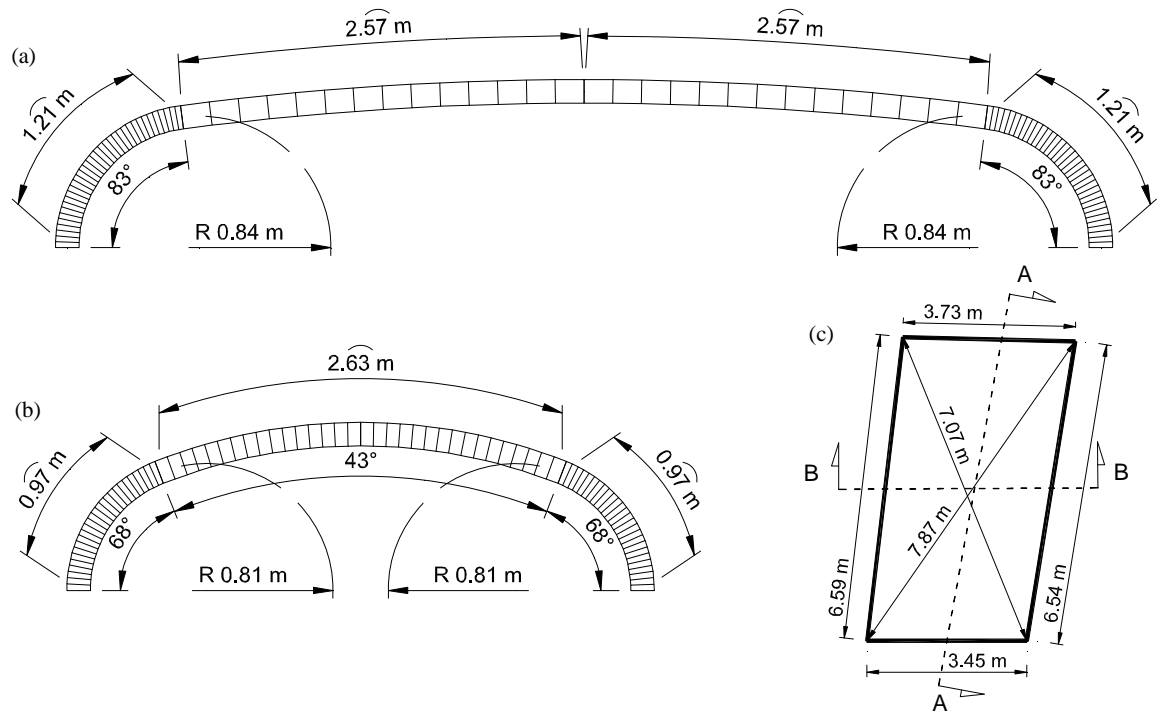

Fig. (3). Longitudinal (a) and transversal (b) polycentric arcs. Plan of the vault (c).

The thickness of vault is measured to be $4 \mathrm{~cm}$. As usual for this kind of structures, it was not possible to take samples for direct evaluation of mechanical parameters. The Italian building code (Instruction Document of Feb. 2nd 2009, n. 617), without a surveys campaign, suggests some values for masonry mechanical parameters. Furthermore, since these are precautionary values characterizing poor quality masonries, the aforementioned code offers correction factors in the case of better conditions as good mortar, limited thickness of joints and so on. Finally, the estimated mechanical parameters are reported in Table $\mathbf{1}$.

Table 1. Mechanical parameters of the masonry vault.

\begin{tabular}{|c|c|}
\hline $\mathrm{f}_{\mathrm{m}}[\mathrm{MPa}]$ & 5.4 \\
\hline$\tau_{0}[\mathrm{MPa}]$ & 0.1125 \\
\hline $\mathrm{E}[\mathrm{MPa}]$ & 3375 \\
\hline $\mathrm{G}[\mathrm{MPa}]$ & 937.5 \\
\hline $\mathrm{W}\left[\mathrm{kN} / \mathrm{m}^{3}\right]$ & 18 \\
\hline
\end{tabular}

In the above table $f_{m}$ is the mean tensile (compressive) strength, $\tau_{0}$ is the mean shear strength, $E$ is the Young modulus, $\mathrm{G}$ is the shear modulus and $\mathrm{W}$ is the density.

\subsection{Modelling of Bare Masonry Vault}

Information about the geometry and the mechanical properties were used to build a linear elastic FE model of the vault. In order to get a good compromise between computational cost and outcomes accuracy, a convergence analysis has been previously performed. To this end, four FE models obtained by successive mesh refinement have been built (Fig. 4). The numerical dimensions of the FE models a), b), c) and d) are presented in the following Table 2 . The convergence analysis is conducted looking at the vertical displacement of the point in the middle of the vault due to the dead loads. The refinement of the mesh, after the model b (see Fig. $\mathbf{4 b}$ ), converge to same response values (as the ones obtained in the refined models shown in the Fig. $\mathbf{4 c}$ and $\mathbf{d}$ ), and consequently the model $\mathrm{b}$ was chosen as the reference 
model because the numerical error in the predicted response due to FE approximation is negligible.

As usual in experimental works and, in particular, in structural monitoring ones, the first issue to be faced is setting up of the sensors placement on the structure relatively to the entities to control. To this purpose, the numerical model may be very useful to predict structural zones where stresses and strains need to be monitored. For the vault in study, a quite complex comparison of deformed shapes, stresses $\left(\sigma_{11}, \sigma_{22}\right.$ and $\left.\sigma_{12}\right)$ and strains $\left(\varepsilon_{22}, \varepsilon_{12}\right.$ and $\left.\varepsilon_{11}\right)$ (Fig. 5a, b) for selfweight, longitudinal and transversal seismic loads has been made. This work allowed the definition of the sensors placement onto the pavilion vault. Fig. (5c) shows the optimal position of the sensors on the plan of the pavilion vault. In this research work, since distributed reinforcement onto the top surface has been designed, the definition of the sensors placement is quite free and related to maximum stresses and strains expected over whole structures differently to the other cases in literature in which, due to the application of concentrated reinforcements, the definition of sensors placement is forced in those points. It is worth describing the strengthening system adopted in this research work.

Table 2. Numerical dimensions of the four FE models depicted in Fig. (4).

\begin{tabular}{|l|c|c|c|c|}
\hline MODEL & a & b & c & d \\
\hline Number of nodes & 963 & 3759 & 14917 & 33475 \\
\hline Number of restrained nodes & 104 & 208 & 416 & 624 \\
\hline Number of shell elements & 925 & 3700 & 14800 & 33300 \\
\hline
\end{tabular}

In common practice, arches and vaults are being strengthened with epoxy-bonded FRP (CFRP or GFRP) strips at the top surface (extrados) intending to lock-out triggering of the most probable failure mechanism. Usually once cracked, the vault changes its behavior to that a system of arches. Even though various types of failures associated with a vaulted structure are possible, the most common one is consequence of a mechanism that undergoes the formation of cylindrical hinges [38].
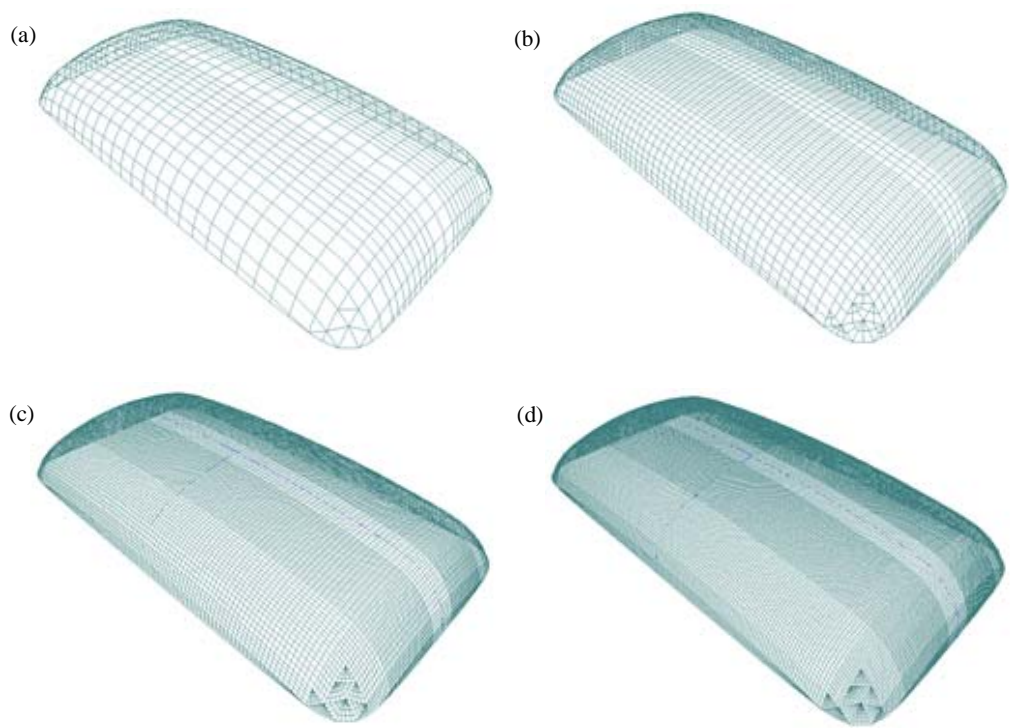

Fig. (4). Four FE models with growing computational effort due to mesh refinement: going from (a) to (d) models.

The application of strip reinforcements, preferably at extrados of the arches, is able to prevent the collapse. It is worth noting, in externally bonded composites the use of epoxy-resins poses some issue, in particular, on masonry breathability and reversibility of the upgrading intervention. The pavilion vault in study has sheet-placed bricks of thickness $4 \mathrm{~cm}$ and, therefore, this structural feature suggests to use a distributed reinforcement over whole surface. The Italian guidelines CNR DT200 [44], for masonry support recommend to use epoxy-bonded FRP textiles or strips as long as its breathability is guaranteed. The aforementioned regulations prescribe a minimum distance between reinforcements. For these reasons and for need of the overall reinforcement, in this case an innovative strengthening 
(a)

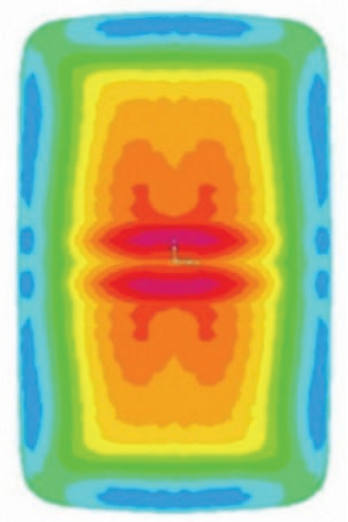

$$
\begin{aligned}
& \sigma_{11 \_\max }=0.096 \mathrm{MPa} \\
& \sigma_{11 \_\min }=-0.216 \mathrm{MPa}
\end{aligned}
$$

(b)
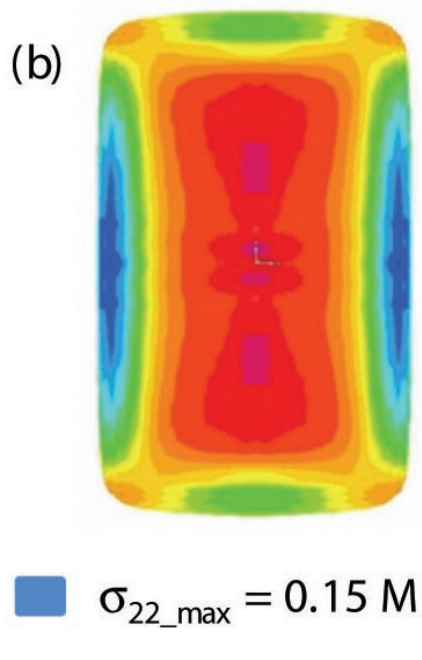

$\sigma_{22 \_ \text {max }}=0.15 \mathrm{MPa}$

$\sigma_{22 \_\min }=-0.175 \mathrm{MPa}$ (c)

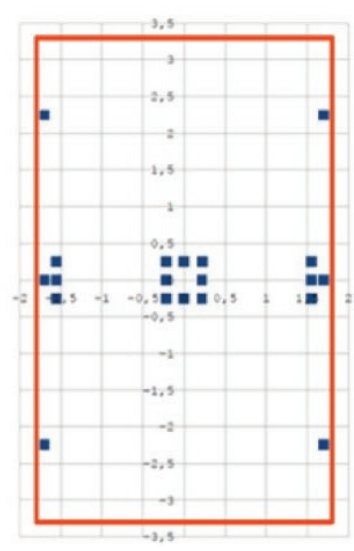

\section{Dimensions in meters}

Fig. (5). Plan view of colors maps for s11 (a) and s22 (b) for dead loads and optimal sensors placement for seismic and dead loads (c).

system has been employed. In the context of widespread reinforcement, in the past, a commonly used method accounted the realization of high stiff extrados r.c. jacketing. However, the recent earthquakes have highlighted their negative effects on the structures. On one hand, they have caused a significant reduction of the self-standing compressive stresses and, on the other, the increment of seismic mass. According to modern retrofitting approaches strengthening philosophy recommend, the solution adopted here provides the reinforcement of the vault and, at the same time, preserves the in plane-deformability properties of the structural element and therefore accommodates small relative displacements at the support of the vault due to the movements of the masonry walls. An increase in stiffness could significantly elevate the internal stresses and create the conditions of triggering local collapse mechanisms. In detail (see Fig. 6), the system chosen consists of a surface application of a thin layer of natural hydraulic lime mortar $(3-4 \mathrm{~cm} \mathrm{max})$ reinforced by fiber glass polymer grid (HLM-GFRP). The inorganic bonding matrix strengthened by fiber grid (carbon, glass, galvanized steel, flax,...) guarantee both the possibility to reinforce the vault, contrasting mechanisms that eventually cause a premature collapse, and, at the same time, not excessive structural stiffening ensuring those deformations necessary in the dynamic case. Furthermore, hydraulic natural lime is chemically compatible with masonry and allows the support to breathe. The FBG sensors are glued on the surface of the GFRP textile grid.

\subsection{Modelling of Strengthened Masonry Vault}

FE modelling of FRP strengthened structures is still an open research field [45 - 47]. Even though the reinforcement behavior is more complex and governed by several elastic constants, in this work it is supposed to be isotropic. Therefore only few parameters have to be determined; they are: the Young modulus E, the Poisson ratio ń and the Shear modulus $\mathrm{G}$ of homogenized material. To take into account the strengthening effect of glued reinforcement a multilayer two-dimensional FE model has been adopted (see Fig 7). Multilayered structures are two-dimensional elements embedding several layers with different mechanical, thermal and electrical properties. As two-dimensional structures we consider those with a dimension, usually the thickness, negligible with respect to the other two in the in-plane directions. Several materials are considered for layers embedded in multilayered structures. A natural development of these are composite materials, where two or more materials are combined on a macroscopic scale in order to obtain better engineering properties than the conventional materials and have desirable properties that cannot be obtained with any of the constituents alone. The analysis of layered structures is a cumbersome subject and multilayer FE theory is still an open research field. Adding layers arises new, different and complicated effects to those that are already known for traditional one layered, isotropic structures. Plates and shells are, by definition, two-dimensional structures, because 
(a)

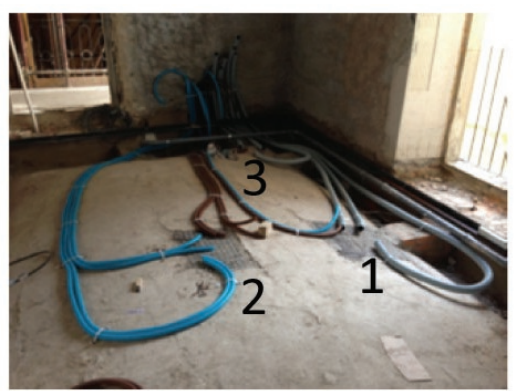

(c)

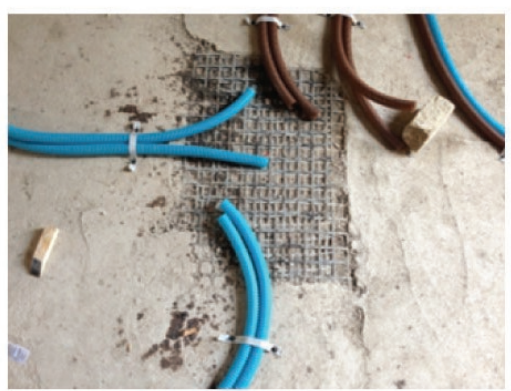

(b)

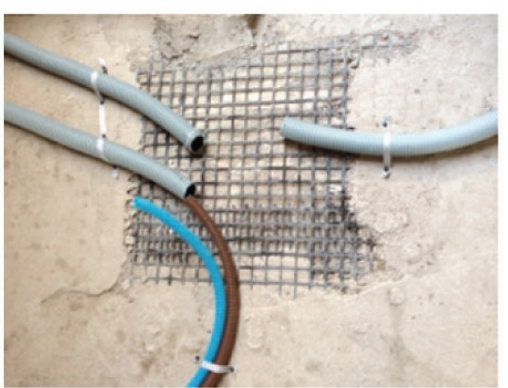

(d)

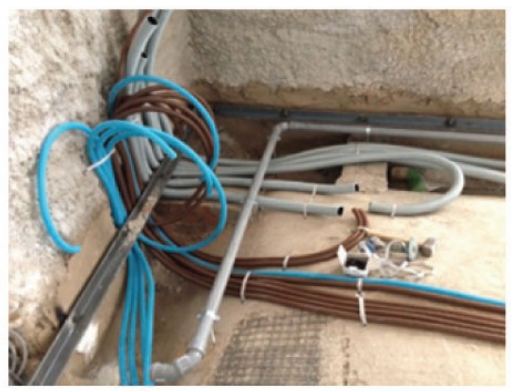

Fig. (6). View of the three selected areas for the insertion of optical sensors. (a) Global view, zoom zone 1 (b), 2 (c), 3 (d).

of one dimension, usually the thickness $h$, is at least of one order of magnitude lower than the representative in plane dimensions $a$ and $b$ measured on the reference plate/shell surface. This fact permits to reduce the 3D problem to a 2D one. Such a reduction can be seen as a transformation of the problem defined in each point $\mathrm{P}_{\Sigma}(\mathrm{x}, \mathrm{y}, \mathrm{z})$ of the 3D continuum occupied by the plate into a problem defined in each point $\mathrm{P}_{\Omega}(\mathrm{x}, \mathrm{y})$ of a reference plate surface $\Omega$. A typical multilayered plate is given in Fig. (7), $(\mathrm{O}, \mathrm{x}, \mathrm{y}, \mathrm{z})$ is an orthogonal coordinate system, $\Omega$ is the middle reference surface of the multilayered structure, $\Omega_{\mathrm{k}}$ is the reference surface for each $k$ layer of thickness $h_{\mathrm{k}}$.

A local orthogonal coordinate system $\left(\mathrm{x}_{\mathrm{k}}, \mathrm{y}_{\mathrm{k}}, \mathrm{z}_{\mathrm{k}}\right)$ can be defined for each layer. In a simple approach, the basic theoretical formulation of the multilayer elements is taken by usual plate/shell one. A generic function to be described within the structure can be postulated in the thickness direction $z[48,49]$ as:

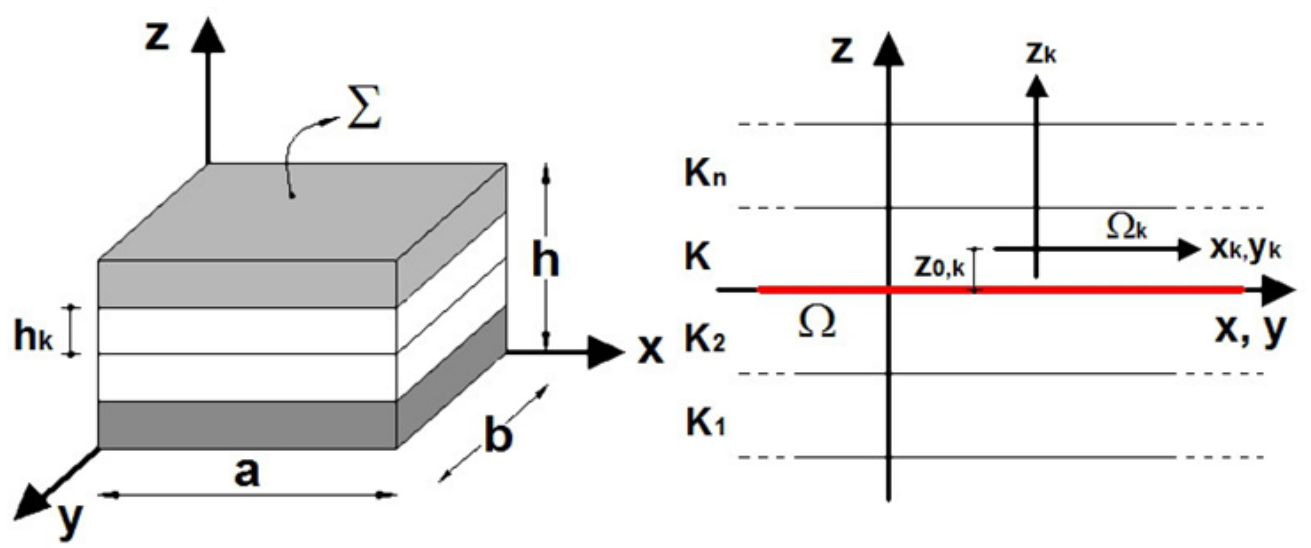

Fig. (7). Geometrical notations for a multilayered plate.

$$
f(x, y, z)=\sum_{i} \sum_{j} F_{j}(z) f_{j}(x, y)
$$

where the generic function $f$ can be the vector of displacements $\mathrm{u}=\left(\mathrm{u}_{\mathrm{x}}, \mathrm{u}_{\mathrm{y}}, \mathrm{u}_{\mathrm{z}}\right)$ in case of a displacement formulation, the vector of strain components $\varepsilon$ in case of a strain formulation and the vector of stress components $\sigma$ in case of a stress 
formulation. Finally, according to equation (5), the entity of interest, for example the displacements, can be written as product of two functions, one depending on the $\mathrm{x}, \mathrm{y}$ coordinates and the other depending on $z$. For the functions, different degree can be assigned. In this context, the main assumption is the $C_{z}$ requirement for the displacements components. In order to describe the in plane behavior, the classical theory for plate/shell can be used. Within the FE code SAP2000, the variation in $z$ direction is described by a linear function. The numerical modelling of reinforcement passes through the assumption of linear elastic isotropic behavior. So, using rules of micromechanics, it is quite straightforward to get the elastic constant of homogenized reinforcement (see Table 3 ).

Table 3. Mechanical parameters of masonry vault.

\begin{tabular}{|c|c|}
\hline $\mathrm{E}[\mathrm{MPa}]$ & 31864.4 \\
\hline ń & 0.23 \\
\hline $\mathrm{G}[\mathrm{MPa}]$ & 12929.84 \\
\hline $\mathrm{W}[\mathrm{kN} / \mathrm{m} 3]$ & 15.6 \\
\hline
\end{tabular}

Here some remarks about the numerical outcomes are being discussed. In the following Fig. (8), maps of max and min stresses for bare and strengthened vault are compared. Fig. (8a and b) show a quite marked ómax stresses unloading on top surface of the masonry vault. Due to perfect interface adherence between structure and composite material, it is observed a migration of stresses toward the stiffener reinforcement layer. The application of HLM-GFRP layer does not affect only the max/min value for stress but also the stresses field distribution.

(a)

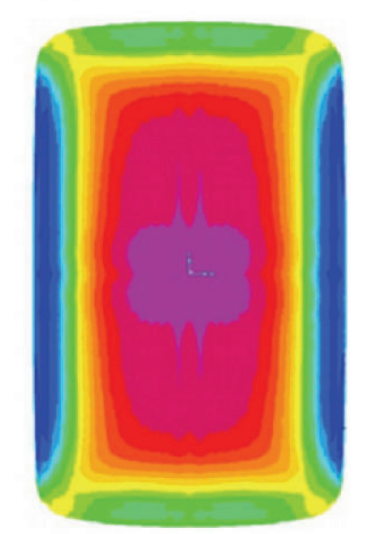

(b)

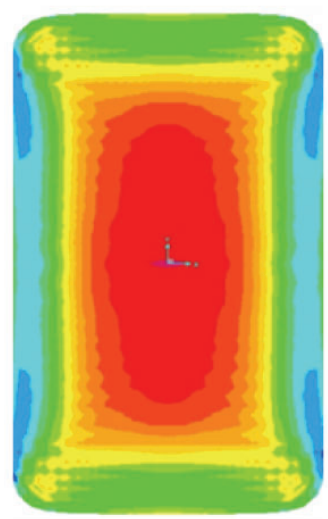

(c)

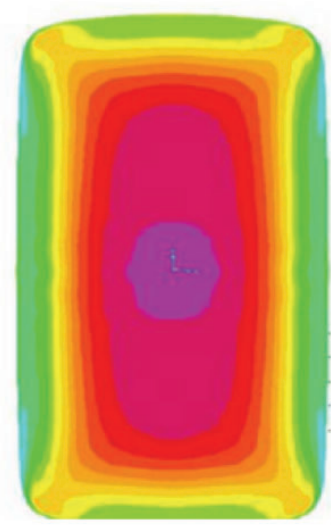

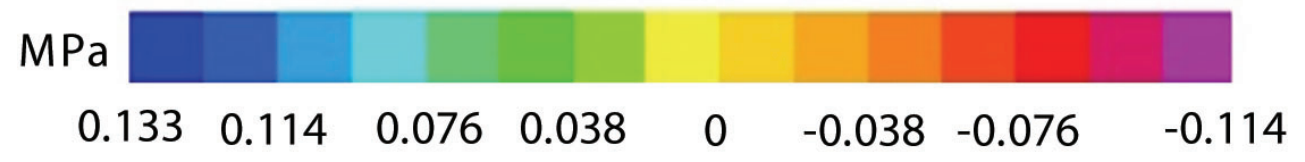

Fig. (8). Color maps for $\sigma_{\max }$ principal stress: (a) masonry extrados of unreinforced case, (b) masonry extrados of reinforced case, (c) median plane of reinforcement layer.

The central zone of unreinforced vault shows a quite uniform compressive stress on the extrados; at the center of the quasi-circular shaped area, the maximum compressive stress is 0,114 MPa (Fig. 8a). In the same area, after the strengthening, the aforementioned max compressive stress is distributed on a wider portion of the structure and it is $0,076 \mathrm{MPa}$ resulting an unloading of the masonry of about $50 \%$ (Fig. 8b). On the lateral sides of the vault the same effect of tensional unloading is observed: tensile stresses undergo a reduction from $0,080 \mathrm{MPa}$ to $0,050 \mathrm{MPa}$ for the shorter edges parallel to the $x$-axis, and from $0,130 \mathrm{MPa}$ to $0,070 \mathrm{MPa}$ for the other ones parallel to the $y$-axis. The improving effect of reinforcement is much more pronounced on the corners of the vault. In these zones, the stress field experiences a sign inversion passing from tensile to compressive stress state. The structural safety, respect to the classical collapse mechanism, is increased since the pressure line is again brought back inside the thickness of masonry. The same considerations can be made analyzing the minimum principal stresses $\sigma_{\min }$. All over the vaulted structure a quite important unloading is still observed. Finally, the changes in color maps suggest that the case of strengthened vault is characterized by better static burden since the concentrated tensional peaks disappear in favor of a more uniform distribution of stresses and consequent their reduction. The unloading in stress field can be observed in whole 
structure and it is as much marked as higher are the stressing actions. The tensional migration toward the stiffener layer represented by the reinforcement may be found in Fig. (8c). In fact, the higher values in magenta affecting the central zone of the vault disappeared in Fig. $(\mathbf{8 c})$, are recovered in the same portion within the strengthening package. This behavior is a consequence of the $C_{z}$ hypothesis on displacement field in multilayer shells theory. Within the knowing process of the vault structural response, qualitative directions may be drawn back by the modal analysis. Moreover, for completeness of the analysis, in the following Fig. (9), the first modal shape and the first frequency for both structures, unreinforced and reinforced are shown.

(a)

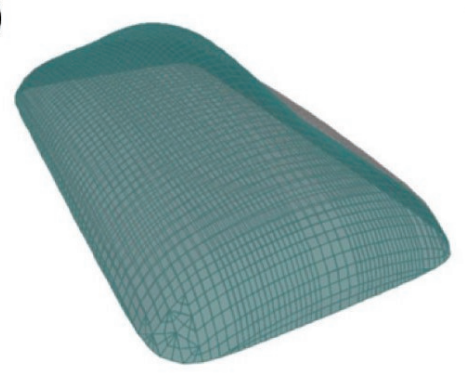

(c)

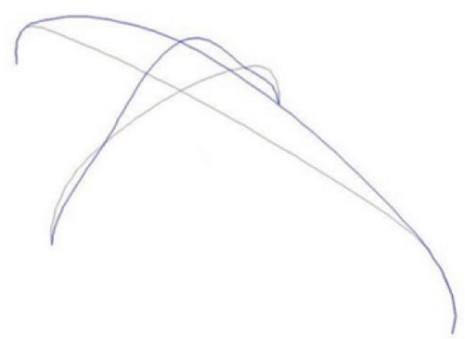

(b)

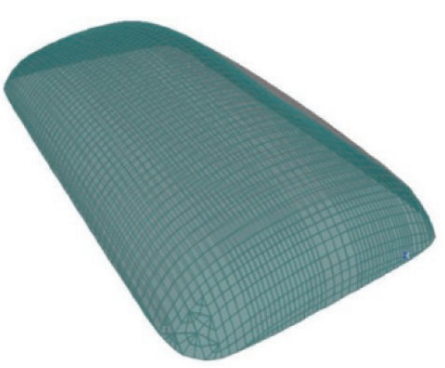

(d)

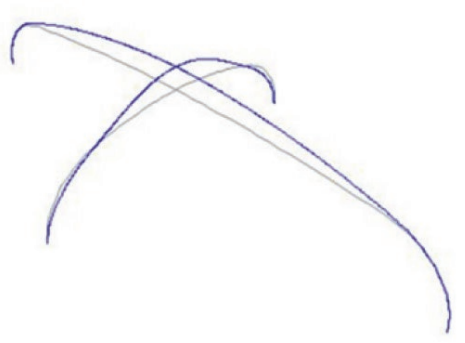

Fig. (9). First modal shape of the unreinforced (a and $\left.\mathbf{c}, \mathrm{f}_{1}=20.27 \mathrm{~Hz} ; \mathrm{M}_{\mathrm{uz}}=22.7 \%\right)$ and reinforced (a and $\mathbf{c}, \mathrm{f}_{1}=22.47 \mathrm{~Hz} ; \mathrm{M}_{\mathrm{uz}}=$ $24.5 \%)$.

In the below Table 4, the modal features of the first five modes are reported.

Table 4. Features of finite elements models: frequencies and Modal Participating Mass Ratios (MPMR).

\begin{tabular}{|c|c|c|c|c|c|c|c|c|}
\hline & \multicolumn{2}{|c|}{ Frequencies [Hz] } & \multicolumn{3}{c|}{ MPMR (UnReinforced) } & \multicolumn{3}{c|}{ MPMR (Reinforced) } \\
\hline MODE & UnReinforced & Reinforced & UX & UY & UZ & UX & UY & UZ \\
\hline 1 & 20.27 & 22.47 & 0,000 & 0,000 & 0,227 & 0,000 & 0,000 & 0,245 \\
\hline 2 & 22,77 & 25,88 & 0,012 & 0,000 & 0,000 & 0,020 & 0,000 & 0,000 \\
\hline 3 & 31,66 & 35,15 & 0,000 & 0,000 & 0,000 & 0,000 & 0,001 & 0,000 \\
\hline 4 & 31,81 & 36,35 & 0,000 & 0,001 & 0,000 & 0,000 & 0,000 & 0,000 \\
\hline 5 & 36,11 & 41,38 & 0,000 & 0,000 & 0,102 & 0,000 & 0,000 & 0,129 \\
\hline
\end{tabular}

The above values show an increment in all vibration frequencies. This is an evidence of the stiffening effect produced by the reinforcement layer glued on the vault extrados. Clearly, considering a certain mode, the modal participating mass related to strengthened structure are increased as well. Comparing the $1^{\circ}$ modal deformed shape of the unreinforced and reinforced structure (see Fig. 9c and d), is visible that in the former case the displacements of the central area are much more pronounced than the latter one. The reason of that stays in the more uniform distribution of the stiffness supplied by the overall strengthening.

\subsection{Critical Aspect of the FBG Sensors Positioning}

The monitoring system is realized by $9+3$ sensors arranged in 3 sets collocated in 3 distinct zones of the vault (see Fig. 6). Each set is formed by 3 strain sensors placed in directions forming an angle of $135^{\circ}$ from each other and one thermal (for measurement compensation). In design monitoring system is needed the definition of the sensors placement both respect to the plane of the structures and, in this case, also respect to the strengthening system. Different types of FBGs application are presented in literature. For example, in monitoring internally placed carbon fiber bars loading the sensors are integrated by means of surface gluing; in monitoring FRP strengthened RC elements, often, the sensors are 
embedded into the polymeric matrix (for this strengthening systems the most probable failure occurs in the surface zone of the concrete). In the present experimental test, each sensor is glued to one grid rod by means of resin (is strictly needed perfect adhesion among the members). The reason of that placement relies in not suitability of measurements on top surface of bonding hydraulic lime due to its null tensile strength. However, since in these new reinforcement systems the bonding matrix is cement or hydraulic lime, the adhesion property in the inter-material surface should be measured as well. Indeed, from monitoring the longitudinal strain of the glass fiber rods forming the grid, using the updated FE model, is still possible derive information about the adhesion of reinforcement layer on the extrados of the vault. If no stresses are measured at the sensors means that the adhesion strength is already exceeded and no strengthening effect is possible. If the measured strain/stress is equal or very close to the predicted numerical outcome means that a good adhesion is present and the reinforcement is supplying strength.

\section{EXPERIMENTAL TEST AND MODEL UPDATING}

Some rapid experimental tests were conducted on the vault to perform a parametric identification of the FE model [50]. The particular condition of the vault, still not reinforced, and the workings the construction site, suggested rapid testing using a wireless sensor network composed by three sensors with triaxial accelerometer. The measured data have acquired the structural dynamic response under a little impulse in $z$-direction and under environmental noise. Two different typologies of experimental setup, shown in the Fig. (10) have been used. In the two configurations the accelerometers have been placed along the middle sections. In particular, one sensor has been collocated in the middle point of the vault and the other two have been positioned respectively to a quarter and three quarters of the length in plan view of two sections.

(a)

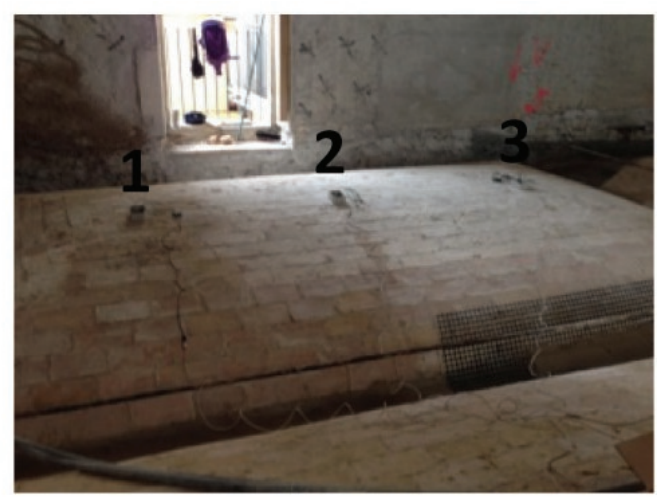

(b)

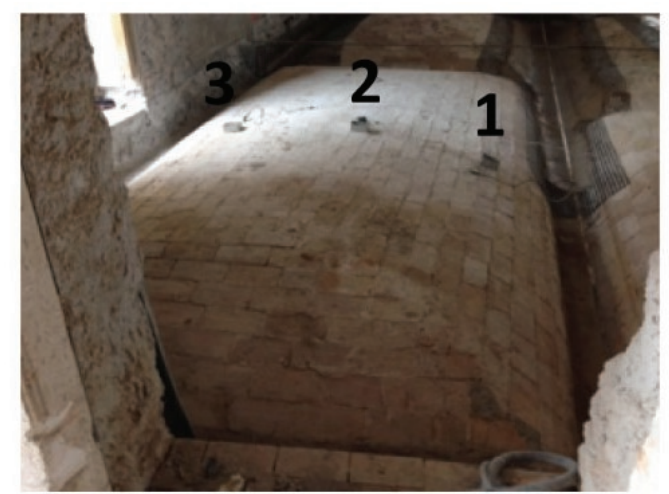

Fig. (10). Two experimental setup: sensors placed along the (a) longitudinal and (b) transversal middle section.

The Fig. (11) shows the experimental response under two different test with little impulse in $z$-direction. The latter was induced using a simple hammer. In the first test the shot was given centrally, i.e. close to sensor 2 (see Fig. 10). However in Fig. (11a) is reported the response of the sensor 1, i.e. the sensor placed to a quarter of the length. Indeed the effect of the wave, transmitted along the whole surface of the vault, has been registered better by the sensor places further away from the starting point of the wave. The same phenomenon happens when the impulse is given in a lateral point, i.e near the sensor 1. In both tests, observing the corresponding PSDs, appears evident the presence of a main peak at a frequency between $16.5 \mathrm{~Hz}$ and $17.5 \mathrm{~Hz}$. In a first approximation, it is right to assume that, at the frequency of $17 \mathrm{~Hz}$, may be associated the first mode of vibration.

Starting from this result of identification, a model updating process has been conducted varying the material characteristics of the model representative of unreinforced case. In particular was followed the variation of the first three modal frequencies varying the elastic modulus. In the below Table 5, after some iteration, a good agreement between the first numerical frequencies and the identified one was reached. In the last step, the elastic modulus has been reduced of about $27 \%$ while the frequency error is of about $1.5 \%$.

Table 5. First three modal frequencies associated with different values of the elastic modulus.

\begin{tabular}{|c|c|c|c|c|}
\hline Models & $\mathbf{E}[\mathbf{k N} / \mathbf{m} 2]$ & $\mathbf{f}_{1}[\mathbf{H z}]$ & $\mathbf{f}_{2}[\mathbf{H z}]$ & $\mathbf{f}_{3}[\mathbf{H z}]$ \\
\hline 0 & 3375000 & 20.27 & 22.77 & 31.66 \\
\hline 1 & 3206250 & 19.76 & 22.20 & 30.86 \\
\hline
\end{tabular}




\begin{tabular}{|c|c|c|c|c|}
\hline Models & $\mathrm{E}[\mathrm{kN} / \mathrm{m} 2]$ & $f_{1}[\mathrm{~Hz}]$ & $\mathrm{f}_{2}[\mathrm{~Hz}]$ & $f_{3}[\mathrm{~Hz}]$ \\
\hline 2 & 3037500 & 19.23 & 21.61 & 30.04 \\
\hline 3 & 2868750 & 18.69 & 21.00 & 29.19 \\
\hline 4 & 2700000 & 18.13 & 20.37 & 28.32 \\
\hline 5 & 2531250 & 17.55 & 19.72 & 27.42 \\
\hline 6 & 2446875 & 17.26 & 19.39 & 26.96 \\
\hline
\end{tabular}
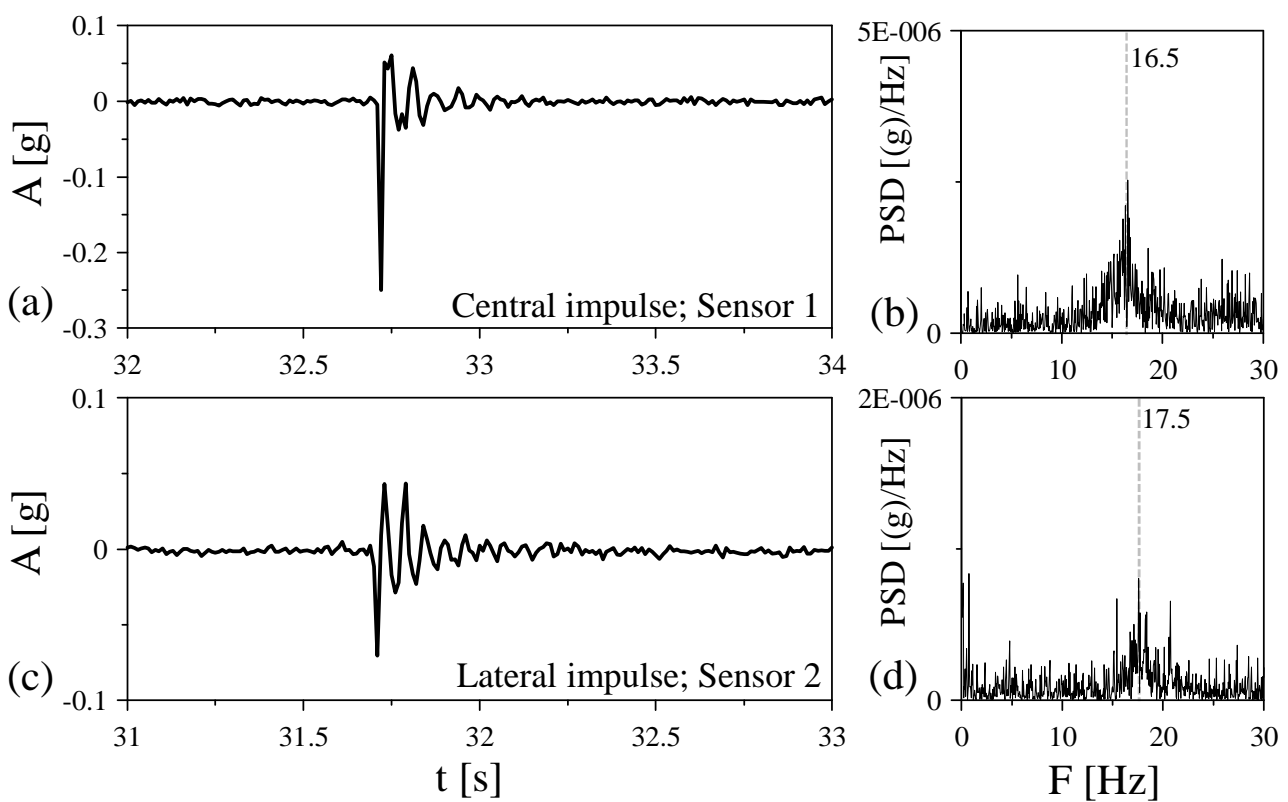

Fig. (11). Dynamic response in $z$-direction and corresponding PSD.

\section{CONCLUSION}

The presented real scale experimental work is part of a retrofitting project regarding an historical building at the center of L'Aquila damaged during the earthquake of April 2009. The study summarizes the findings of the ongoing design phase to develop smart strengthening systems. Several aspects are faced. FE models of the structures in unreinforced and reinforced configuration have been developed using multilayer theory to model the distributed reinforcement posed in the upper part of the vault. The model updating based on modal testing has offered the possibility of reasonable numerical predictions of the real behavior. Furthermore, information has been given about the ability of reinforcement to supply strength and adhesion property of the bonding grout. The measurements can be used also as early warning on structural safety. However, in this research the stress and stain prediction for seismic loads it could be valid in very limited range as, in the developed FE models, a linear elastic behavior hypothesis is assumed for the all materials constituting the analyzed structural system. For this reason, further efforts and research activities could be focalized on the development of a more accurate modelling, i.e. able to take into account both the nonlinear masonry behavior [51,52] and the strongly nonlinear phenomena (detachments, friction effects) occurring at the reinforcemasonry support interface [45 - 47]. From technical point of view, an improvement could be get by introducing transversal glass fiber connectors between the masonry vault and the strengthening layer.

\section{CONFLICT OF INTEREST}

The authors confirm that this article content has no conflict of interest.

\section{ACKNOWLEDGEMENTS}

This research has been possible thanks to the financial support of TIRARE, a L'Aquila construction company network, the start-up of which has been supported by Abruzzo Region for developing innovative strategies for seismic retrofitting of masonry historic building. Funding by RELUIS-DPC 2014 and by the Italian Ministry of Education, Universities and Research (MIUR) through the PRIN funded program "Dynamics, Stability and Control of Flexible 
Structures"(Grant no. 2010MBJK5B) are also acknowledged.

\section{REFERENCES}

[1] C.E. Bakis, L.C. Bank, V.L. Brown, E. Cosenza, J.F. Davalos, J.J. Lesko, A. Machida, S.H. Rizkalla, and T.C. Triantafillou, "FiberReinforced Polymer Composites for Construction-State of the Art Review", Journal of Composites in Constructions, vol. 6, no. 2, pp. 73-82, 2002 .

[http://dx.doi.org/10.1061/(ASCE)1090-0268(2002)6:2(73)]

[2] R Fangueiro, Fibrous and Composite Materials for Civil Engineering Application, $1^{\text {st }}$ ed. Woodhead Publishing: Sawston, Cambridge, 2011. [http://dx.doi.org/10.1533/9780857095583]

[3] D. Chandramohan, and K. Marimuth, "A review on natural fibers", International Journal of Research and Reviews in Applied Sciences, vol. 8, no. 2, pp. 196-206, 2011.

[4] C.W. Dolan, "FRP Prestressing in the USA", Concrete International, vol. 21, no. 10, pp. 21-24, 1999.

[5] L.R. Taerwe, and S. Matthys, FRP for concrete construction. Concrete International, vol. 21. 1999, no. 10, pp. 33-36.

[6] A. Nanni, Fiber-Reinforced-Plastic for Concrete Structures: Properties and Applications. Elsevier Science: Amsterdam, 1993.

[7] E. Cosenza, G. Manfredi, and R. Realfonzo, "Behavior and modeling of bond of FRP rebars to concrete", Journal of Composites for Constructions, vol. 1, no. 2, pp. 40-51, 1997.

[http://dx.doi.org/10.1061/(ASCE)1090-0268(1997)1:2(40)]

[8] H.V. GangaRao, and P.V. Vijay, "Design of concrete members reinforced with GFRP bars", In: Proceedings of $3^{\text {rd }}$ International Symposium, Fiber Reinforced Polymer Reinforcement for Reinforced Concrete Structures, vol. 1. Japan Concrete Institute: Tokyo, 1997, pp. 143-150.

[9] U. Meier, "Bridge repair with high performance composite materials", Material and Technik, vol. 4, Duebendorf,Switz(in German), pp. 125-128, 1987.

[10] F.S. Rostasy, "Bonding of Steel and GFRP Plates in the Area of Coupling Joints", Talbrucke Kattenbusch, Research Report No. 3126/1429, Federal Institute for Materials Testing, Braunschweig, Germany, 1987.

[11] M.N. Fardis, and H. Khalili, "Concrete encased in fiberglass reinforced plastic", ACI Journal, vol. 78, no. 6, pp. 440-446, 1981.

[12] H. Katsumata, Y. Kobatake, and T. Takeda, "A study on the strengthening with carbon fiber for earthquake-resistant capacity of existing reinforced concrete columns", In: Proceedings of the Workshop on Repair and Retrofit of Existing Structures, U.S.-Japan Panel on Wind and Seismic Effects. U.S.-Japan Cooperative Program in Natural Resources: Tsukuba, Japan, 1987, pp. 1816-1823.

[13] T.C. Triantafillou, and C.P. Antonopoulos, "Design of concrete flexural members strengthened in shear with FRP", Journal of Composites for Constructions, vol. 4, no. 4, pp. 198-205, 2000. [http://dx.doi.org/10.1061/(ASCE)1090-0268(2000)4:4(198)]

[14] E. Shehata, R. Morphy, and S. Rizkalla, "Fiber reinforced polymer shear reinforcement for concrete members: behavior and design guidelines", Canadian Journal of Civil Engineering, vol. 27, no. 5, pp. 859-872, 2000. [http://dx.doi.org/10.1139/100-004]

[15] A.J. Lamanna, L.C. Bank, and D.W. Scott, "Flexural strengthening of reinforced concrete beams using fasteners and fiber reinforced polymer strips", ACI Structural Journal, vol. 98, no. 3, pp. 368-376, 2001

[16] L.C. Bank, and M. Ozel, "Shear failure of concrete beams reinforced with 3-D fiber reinforced plastic grids", C. W. Dolan, S. H. Rizkalla, and A. Nanni, Eds., In: Proceedings of $4^{\text {th }}$ International Symposium on Fiber Reinforced Polymer Reinforcement for Reinforced Concrete Structures, SP-188. American Concrete Institute: Farmington Hills, Mich., 1999.

[17] A. Mirmiran, M. Shahawy, M. Samaan, H. El Echary, J.C. Mastrapa, and O. Pico, "Effect of column parameters on FRP-confined concrete", ACI Structural Journal, vol. 2, no. 4, pp. 175-185, 1998. [http://dx.doi.org/10.1061/(ASCE)1090-0268(1998)2:4(175)]

[18] G. Schwegler, "Masonry construction strengthened with fiber composites in seismically endangered zones", In: G. Duma, Ed., Proceedings of $10^{\text {th }}$ European Conference on Earthquake Engineering, vol. 3. Balkema: Rotterdam, The Netherlands, 1994, pp. $2299-2304$.

[19] T.C. Triantafillou, "Strengthening of masonry structures using epoxy-bonded FRP laminates", Journal of Composites for Constructions , vol. 2, no. 2, pp. 96-104, 1998.

[http://dx.doi.org/10.1061/(ASCE)1090-0268(1998)2:2(96)]

[20] T.C. Triantafillou, and M.N. Fardis, "Strengthening of historic masonry structures with composite materials", Materials and Structures, vol. 30, pp. 486-496, 1997.

[http://dx.doi.org/10.1007/BF02524777]

[21] A. Borri, A. Avorio, and M. Bottardi, "Theoretical analysis and a case study of historical masonry vaults strengthened by using advanced FRP", In: J. L. Humar, and A. G. Razaqpur, Eds., Proceedings of $3^{\text {rd }}$ International Conference on Advanced Composite Materials in Bridges and Structures. Canadian Society for Civil Engineering: Montreal, Quebec, 2000, pp. 577-584.

[22] P. Faccio, and P. Foraboschi, "Advanced Composite Materials in Bridges and Structures III", In: J. Humar, and A.G. Razaqpur, Eds., Experimental and Theoretical Analysis of Masonry Vaults with FRP Reinforcements. Canadian Society for Civil Engineering, 2000, pp. $629-636$. 
[23] E. Grande, G. Milani, and E. Sacco, "Modelling and analysis of FRP-strengthened masonry panels", Engineering Structures, vol. 30, pp. $1842-1860,2008$ [http://dx.doi.org/10.1016/j.engstruct.2007.12.007]

[24] N. Plevris, and T.C. Triantafillou, "FRP-reinforced wood as structural material", Journal of Materials in Civil Engineering, vol. 4, no. 3, pp. 300-317, 1992. [http://dx.doi.org/10.1061/(ASCE)0899-1561(1992)4:3(300)]

[25] P. Qiao, J.F. Davalos, and M.G. Zipfel, "Modeling and optimal design of composite-reinforced wood railroad crosstie", Composites Structures, vol. 41, no. 1, pp. 87-96, 1998. [http://dx.doi.org/10.1016/S0263-8223(98)00051-8]

[26] V.M. Karbhari, and S.B. Shulley, "Use of composites for rehabilitation of steel structures - Determination of bond durability", Journal of Materials in Civil Engineering, vol. 7, no. 4, pp. 239-245, 1995. [http://dx.doi.org/10.1061/(ASCE)0899-1561(1995)7:4(239)]

[27] X. Liu, P.F. Silva, and A. Nanni, "Rehabilitation of steel bridge members with FRP composite materials", In: Proceedings of Composites in Construction. Porto, Portugal, 2001, pp. 613-617.

[28] M. Tavakkolizadeh, "Strengthening of steel-concrete composite girders using carbon fiber reinforced polymers sheets", Journal of Structural Engineering, vol. 129, no. 1, pp. 30-40, 2003. [http://dx.doi.org/10.1061/(ASCE)0733-9445(2003)129:1(30)]

[29] M. Sun, W.J. Staszewski, and R.N. Swamy, "Smart sensing Technologies for Structural Health Monitoring of Civil Engineering Structures", Advances in Civil Engineering, vol. 2010, 2010. [http://dx.doi.org/10.1155/2010/724962]

[30] C.B. Yun, and J. Min, "Smart sensing, monitoring and damage detection for civil infrastructures", KSCE Journal of Civil Engineering, vol. 15, no. 1, pp. 1-14, 2010. [http://dx.doi.org/10.1007/s12205-011-0001-y]

[31] C. Lawrence, D. Nelson, T. Bennet, and J. Spingard, "Determination of process-induced residual stress in composite materials using embedded fiber optic sensors", In: Proceedings of SPIE, vol. 3042. 1997, pp. 65-154. [http://dx.doi.org/10.1117/12.275732]

[32] T. Horiguchi, T. Kurashim, and M. Tateda, "Tensile strain dependence of Brillouin frequency shift in silica optical fibers", IEEE Photonics Technology Letters, vol. 1, no. 5, pp. 108-107, 1989. [http://dx.doi.org/10.1109/68.34756]

[33] W. Morey, G. Meltz, and W.H. Glenn, "Fiber optic Bragg grating sensors", In: Proceeding of SPIE, vol. 1169. 1989, pp. 98-107. [http://dx.doi.org/10.1117/12.963022]

[34] W.L. Schulz, J. Conte, and E. Udd, "J.M. Seim, "Static and dynamic testing of bridges and highways using long-gage fiber Bragg grating based strain sensors", In: Proceedings of SPIE, vol. 4202. 2000, pp. 79-86. [http://dx.doi.org/10.1117/12.411730]

[35] A.L. Kalamkarov, S.B. Fitzgerald, D.O. MacDonald, and A.V. Georgiades, "On the processing and evaluation of pultruded smart composites", Composites, Part B, vol. 30, pp. 753-763, 1999. [http://dx.doi.org/10.1016/S1359-8368(99)00037-2]

[36] K. Lau, L. Yuan, L. Zhou, J. Wu, and C. Woo, "Strain monitoring in FRP laminates and concrete beams using FBG", Composite Structures, vol. 51, pp. 9-20, 2001.

[http://dx.doi.org/10.1016/S0263-8223(00)00094-5]

[37] Y. Wang, Q. Hao, and J. Ou, "Experimental testing of a self-sensing FRP-concrete composite beam using FBG sensors", In: Proceedings of Sensors and Smart Structures Technologies for Civil, Mechanical and Aerospace Systems, SPIE, vol. 7292. 2009 , pp. 72923T-1.

[38] F. Bastianini, M. Corradi, A. Borri, and A. Di Tommasi, "Retrofit and monitoring of an historical building using "Smart" CFRP with embedded fibre optic Brillouin sensors", Construction and Building Materials, vol. 19, pp. 525-535, 2005. [http://dx.doi.org/10.1016/j.conbuildmat.2005.01.004]

[39] "Polyfunctional Technical Textiles against Natural Hazards (POLYTECT)", Report, 2010. Available from: http://cordis.europa.eu/ project/ren/81556_en.html

[40] E. Mehrani, A. Ayoub, and A. Ayoub, "Evaluation of fiber optic sensors for remote health monitoring of bridge structures", Materials and Structures, vol. 42, pp. 183-199, 2009. [http://dx.doi.org/10.1617/s11527-008-9377-7]

[41] K.T. Lau, L.M. Zhou, and J.S. Wu, "Investigation on strengthening and strain sensing techniques for concrete structures using FRP composites and FBG sensors", Materials and Structures, vol. 34, pp. 42-50, 2001. [http://dx.doi.org/10.1007/BF02482199]

[42] S. Kaseberg, M.B. Schaller, and K. Holschemacher, "CFRP Systems with embedded FBG for structural monitoring and retrofitting", In: Proceeding of $6^{\text {th }}$ European Workshop on Structural Health Monitoring. 2012. Dresden (Germany) Fr.2.B1. Available from: http://www.ndt.net/article/ewshm2012/papers/fr2b1.pdf 
[43] M. Majumder, T.K. Gangopadhyay, A.K. Chakraborty, K. Dasgupta, and D.K. Bhattacharya, "Fibre Bragg gratings in structural health monitoring-Present status and applications", Sensors and Actuators A: Physical, vol. 147, pp. 150-164, 2008. [http://dx.doi.org/10.1016/j.sna.2008.04.008]

[44] C.E Bakis, A. Ganjeholue, M. Schupack, and PN. Balaguru, Guide for the Design and Construction of Externally Bonded FRP Systems for Strengthening of Existing Structures. Rome: CNR, 2004.

[45] E. Sacco, and J. Toti, "Interface elements for the analysis of masonry structures", International Journal for Computational Methods in Engineering Science and Mechanics, vol. 11, pp. 354-373, 2010. [http://dx.doi.org/10.1080/15502287.2010.516793]

[46] S. Marfia, E. Sacco, and J. Toti, "A coupled nonlocal interface damage model for FRP strengthening detachment", Computational Mechanics, vol. 50 , no. 3 , pp. $335-351,2012$.

[http://dx.doi.org/10.1007/s00466-011-0592-7]

[47] J. Toti, S. Marfia, and E. Sacco, "Coupled body-interface nonlocal damage model for FRP detachment", Computer Methods in Applied Mechanics and Engineering, vol. 260, pp. 1-23, 2013. [http://dx.doi.org/10.1016/j.cma.2013.03.010]

[48] E. Carrera, "Theories and finite elements for multilayered plates and shells: A unified compact formulation with numerical assessment and benchmarking", Archives of Computational Methods in Engineering, vol. 10, no. 3, pp. 215-296, 2003. [http://dx.doi.org/10.1007/BF02736224]

[49] A.M. Ceci, "Modelling of Multilayer Two-Dimensional Structures with Non-Linear Consitutive Law", PhD Thesis, Engineering and Mathematical-Physical, University of L'Aquila, L'Aquila, Italy, 2013.

[50] D. Foti, V. Gattulli, and F. Potenza, "Output-only identification and model updating by dynamic testing in unfavorable conditions of a seismically damaged building", Computer-Aided Civil and Infrastructure Engineering, vol. 29, pp. 659-675, 2014. [http://dx.doi.org/10.1111/mice.12071]

[51] D. Addessi, M. Marfia, E. Sacco, and J. Toti, "Modeling approaches for masonry structures", Open Civil Engineering Journal, vol. 8, no. 1, pp. 288-300, [http://dx.doi.org/10.2174/1874149501408010288]

[52] J. Toti, V. Gattulli, and E. Sacco, "Nonlocal damage propagation in the dynamics of masonry elements", Computer Structures, vol. 152, pp. 215-227, 2015.

[http://dx.doi.org/10.1016/j.compstruc.2015.01.011]

(C) Gattulli et al. ; Licensee Bentham Open.

This is an open access article licensed under the terms of the Creative Commons Attribution-Non-Commercial 4.0 International Public License (CC BY-NC 4.0) (https://creativecommons.org/licenses/by-nc/4.0/legalcode), which permits unrestricted, non-commercial use, distribution and reproduction in any medium, provided the work is properly cited. 